\title{
Complete Blockage Device
}

National Cancer Institute

\section{Source}

National Cancer Institute. Complete Blockage Device. NCI Thesaurus. Code C63024.

Problem related to an obstruction or blockage within the device component (e.g. tube, opening, pipe) that results in no flow. 